\title{
Synthesis, Characterization and Pharmacological Evaluation of Biphenyl Based 4-Thiazolidinones
}

\author{
Monika Shirke', Monali Gangthade', Pratip Chaskar², Rakesh Somani ${ }^{2, *}$ \\ ${ }^{1}$ Department of Pharmaceutical Chemistry, Vivekanand Education Society College of Pharmacy, Chembur, \\ Mumbai, Maharashtra, INDIA. \\ ${ }^{2}$ Department of Pharmaceutical Chemistry, DY Patil University School of Pharmacy, Affiliated to DY Patil (Deemed to be University), \\ Nerul, Navi Mumbai, Maharashtra, INDIA.
}

\begin{abstract}
Background: Biphenyl based 4-thiazolidinones are found to possess a wide range of activities resulting in their synthesis. Methods: Eight molecules (VIla-VIlh) were profoundly synthesized using four step procedures. These 4-thiazolidinone derivatives were characterized by elemental analysis ( $\mathrm{CHN}$ ) and spectral (IR and ${ }^{1} \mathrm{H} N \mathrm{NMR}$ ) analysis. All the compounds were evaluated for their in vitro antimicrobial activity against one Gram negative strain (Escherichia coll) and two Gram positive strains (Bacillus subtilis and Staphylococcus aureus) and two fungal strains (Candida albicans and Aspergillus niger). Results: The results of antimicrobial studies revealed that compounds (VIIg) possessed moderate antifungal activity and compounds (VIIc and VIle) showed good antibacterial activity against fungal and bacterial strain respectively. Conclusion: Compounds containing electron withdrawing groups $\left(-\mathrm{NO}_{2},-\mathrm{Cl},-\mathrm{Br}\right)$ on the aromatic ring showed improved antimicrobial activity.
\end{abstract}

Key words: Biphenyl based 4-thiazolidinone, Antimicrobial, Antibacterial, Antifungal, Schiff's bases.

\section{INTRODUCTION}

Until the seventies of the $20^{\text {th }}$ century, microbial infections were rather easily cured and the need for new antimicrobial drugs was low. Choice of antimicrobial was preparations, toxicity and limited spectrum of action and the risk of resistant strains proved the need of new effective medicines for systemic microbial diseases. The incidences of microbial infections have increased over the last two decades leading to superficial illness to life threatening diseases. ${ }^{1}$

If atleastone atom other than carbon forming the part of a ring system is replaced by other atom, then it is designated as a heterocyclic compound. Of the various divisions of organic chemistry which are assumed to have immense biological and industrial importance, heterocyclic chemistry has a major share. There are many heterocycles of natural origin e.g. reserpine, theophylline, etc. ${ }^{2}$ Even biological processes which are essentially chemical reactions, utilize various heterocycles such as vitamins, 90-cnzymes, ATP, serotonin, etc. for their completion. Also, these exhibit a striking structural feature which is inherent to all heterocycles viz: ability to manifest substituents around the core scaffold in a defined manner. ${ }^{3}$ Hence, heterocycles are of great interest in organic synthesis. Heterocyclic compounds containing nitrogen, sulphur and oxygen, have been explored widely for application in drug industry. ${ }^{4}$

The need of new compounds is satisfied by searching leads through different sources hike natural, marine, synthetic route, etc. Amongst the synthetic routes, heterocyclic compounds represents one of the most active classes of compounds possessing a wide spectrum of biological activities, ${ }^{5}$ including antibacterial, ${ }^{6,7}$ antimicrobial, ${ }^{8}$ anti-HIV, etc. However, nitrogen and sulphur containing compounds like biphenyl
Submission Date: 10-06-2020; Revision Date: 18-09-2020; Accepted Date: 13-03-2021

DOI: 10.5530/ijper.55.2.74 Correspondence: Dr. Rakesh Somani DY Patil University School of Pharmacy, Affiliated to DY Patil Deemed to be University, Nerul, Navi Mumbai, Maharashtra, INDIA.

Phone no: +91-9833771384 Email id: rakeshrsomani@ gmail.com

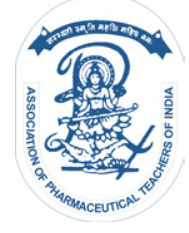

www.ijper.org 
based 4-thiazolidinones ${ }^{10}$ are well famed for their broad spectrum of biological activities.4-thiazolidinone is a derivative of thiazolidine with a carbonyl group at $4^{\text {th }}$ position heterocyclic compounds. The methylene carbon an important group of atom at fifth position possesses nucleophilic activity and attacks on electrophilic centre. The reaction loses water by forming 5 membered unsaturated derivatives 4-thiazolidinone. The Instrument facility reaction occurs in presence of a base and the anion of the 4-thiazolidinone is the attacking species. ${ }^{11}$ The ease of formation of the anion and hence the degree of the nucleophilic activity is dependent not only on the electron withdrawing effect of the adjacent carbonyl group, but also on the presence of other electron withdrawing groups such as those attached to the second carbon atom. ${ }^{12}$

\section{MATERIALS AND METHODS}

\section{Materials}

All the chemicals like thioglycollic acid, hydrazine hydrate, thionyl chloride and solvents were purchased from Loba Chem, Mumbai. 1,1-Biphenyl 4-carboxylic acid was purchased from Sigma Aldrich, Mumbai. The identity of all the compounds was confirmed by taking the melting point and the purity by TLC where a single spot was observed. Solvents were used after distillation throughout the course of the work. Melting points of all the intermediates and the final products were recorded using open capillary tube method on Veego-VMP-D apparatus. Purity of the compounds and reaction progress was monitored by TLC, using silica gel G plates of size $3 \times 8 \mathrm{~cm}$ (Sigma Aldrich) using suitable solvent system and was visualized under UV radiation. The FTIR spectra were recorded in the $4000-400 \mathrm{~cm}^{-1}$ range using Shimadzu FTIR Infinity Spectrometer. ${ }^{1} \mathrm{H}-\mathrm{NMR}$ spectra were recorded on Varian Mercury $(600 \mathrm{mHz})$ and Bruker Avance II (400 mHz) using DMSO- $\mathrm{d}_{6}$ and $\mathrm{CDCl}_{3}$, as solvents and TMS was internal standard. ${ }^{1} \mathrm{H}$ NMR and Mass spectra studies was outsourced from Sophisticated Analytical Instrument facility (SAIF), Punjab. Purification of intermediate and final products was performed by techniques such as re-crystallization or column chromatography using appropriate solvents and solvent systems as per requirements.

\section{Methods for synthesis of title compounds (VIla-VIIh)}

Step 1: General procedure for synthesis of
1,1-Biphenyl 4-carbonyl chloride (II) 1,1-Biphenyl 4-carbonyl chloride (II)

1,1-Biphenyl 4-carboxylic acid (I) (1.98 g, $0.01 \mathrm{~mol}$ ) was taken in a $250 \mathrm{ml}$ round bottom flask. Thionyl chloride $(1.45 \mathrm{~mL}, 0.02 \mathrm{~mol})$ was added drop wise within a period of $1 \mathrm{~h}$. The mixture then refluxed with continuous stirring for 3 to $4 \mathrm{~h}$. The progress of the reaction was monitored by TLC at regular intervals using ethyl acetate and hexane (1:1) as a solvent system. Single spot indicated the completion of step 1 reaction and formation of a brown coloured 1,1-Biphenyl-4carbonyl chloride (II). The crude product was then recrystallized with ethanol.

\section{Step 2: Synthesis of 1,1-Biphenyl 4-carboxylic acid hydrazide (III)}

1,1-Biphenyl-4-carbonyl chloride (II) (1.75 g, 0.008 $\mathrm{mol})$ was treated with hydrazine hydrate $(3 \mathrm{~mL}, 0.024$ $\mathrm{mol})$. The mixture was then refluxed for $2-3 \mathrm{~h}$ and the progress of reaction was monitored by TLC at regular interval using ethyl acetate and hexane (1:1) as a solvent system. After completion of the reaction, the reaction mixture was cooled to room temperature and was then poured in a beaker containing $50 \mathrm{~mL}$ ice cold water and was kept for stirring for 1-2 $\mathrm{h}$. The solid thus obtained was separated, filtered and washed with water to yield 1,1-Biphenyl 4-carboxylic acid hydrazide (III). The crude product was then recrystallized with ethanol.

\section{Step 3: Synthesis of 1,1-Biphenyl 4-carboxylic acid hydrazone (Schiff's Bases) (Va-Vh)}

A mixture of 1,1-Biphenyl 4-carboxylic acid hydrazide (III) $(0.55 \mathrm{~g}, 0.002 \mathrm{~mol})$ and the corresponding aromatic aldehyde (IV) (0.003 mol) was dissolve in $10 \mathrm{~mL}$ ethanol. Glacial acetic acid was added to the reaction mixture in catalytic amount and it was refluxed for 5-7 h. The reaction was monitored to completion by TLC using ethyl acetate and hexane (1:1) as solvent system. The compounds $(\mathrm{Va}-\mathrm{Vh})$ were obtained by pouring the reaction mixture into a beaker containing ice cold water. The solid, thus obtained was separated by filtration and dried at room temperature. The crude product was then recrystallized using ethanol.

\section{Step 4: Synthesis of 4-Thiazolidinone derivatives (VIIa-VIIh)}

1,1-Biphenyl 4-carboxylic acid hydrazide hydrazine (Schiff's bases) (Va-Vh) (0.001 mol) was dissolved in ethanol. Thioglycolic acid (VI) (0.11 mL, $0.009 \mathrm{~mol})$ and zinc chloride was added to the reaction mixture in catalytic amount and refluxed for 6-7 h. The reaction was monitored to completion by TLC using ethyl acetate and hexane (1:1) as solvent system. The compound (VIIa-VIIh) were obtained by pouring the reaction mixture into a beaker containing ice cold water. The solid, compound obtained was separated by filtration 
and dried at room temperature. The crude product was then recrystallized with ethanol.

By adopting similar type of procedures and employing equimolar quantities of reactants, eight compounds were synthesized. Synthetic pathway for preparation of title compounds is Scheme 1.

\section{Spectral analysis of title compounds (VIla-VIIh).}

The structures of the synthesized compounds (VIIaVIIh) were confirmed by elemental analysis and IR spectra (KBr pellet technique). ${ }^{1} \mathrm{H}$ NMR (DMSO-d and $\mathrm{CDCl}_{3}$ as solvents and TMS was internal standard), Mass spectral analysis and elemental analysis (carbon, hydrogen, nitrogen) was carried out for representative compounds.

\section{Antimicrobial evaluation of title compounds (VIla-VIIh)}

The synthesized compounds (VIIa-VIIh) were evaluated for their antimicrobial method by disc diffusion method. ${ }^{13,14}$ The antibacterial activity was screened against Stapbylococcus aureus, Escherichia coli and Bacillus subtilis and antifungal activity against Aspergillus niger and Candida albicans by using Ciprofloxacin and Fluconazole as standard drugs respectively.

Media Used - Brain Heart Infusion agar media was used for antibacterial activity. In the anti-fungal disc diffusion method, the Sabouraud agar medium was used.

Temperature - Brought agar plates to room temperature before used.

Inoculum preparation - A loop or swab was used to transfer the colonies to the plates. The turbidity was adjusted visually with the broth equal to that of a 0.5 McFarland turbidity standard that has been vortexed. Alternatively, it the suspension was standardized with a photometric device.

Inoculation of Agar plate - Within 15 min of inoculum adjustment to McFarland 0.5 turbidity standard, sterile cotton swab was dipped into the inoculum and rotated against the wall of the tube above the liquid to remove excess inoculum. The entire surface of agar plate was swabbed three times and the plates were rotated to approximately $60^{\circ}$ between streaking to ensure even distribution, avoiding hitting the sides of the Petri plate and aerosols were created. The inoculated plates were allowed to stand for at least $3 \mathrm{~min}$ but no longer than 15 min before made wells.

Stock solution preparation - The stock solution was prepared by dissolving $10 \mathrm{mg}$ of compound in $1 \mathrm{~mL}$ of DMSO.
Addition of compound into plate - A hollow tube of $5 \mathrm{~mm}$ diameter was heated and was pressed above inoculated Agar plate to remove it immediately by making a well in the plate. Likewise, five wells were made on each plate. With the help of micropipette 75 $\mu \mathrm{l}, 50 \mu \mathrm{l}, 25 \mu \mathrm{l}, 10 \mu \mathrm{l}$ and $5 \mu \mathrm{l}$ sample was added in each well.

Incubation - The plates were incubated within $15 \mathrm{~min}$ of compound application. The plates were inverted and were incubated for $18-24 \mathrm{~h}$ at $37^{\circ} \mathrm{C}$ in an incubator.

Reading plates - The plates were read only if the lawn of growth was confluent or nearly confluent. The diameter of inhibition zone was measured to the nearest whole millimeter by holding the measuring device.

\section{RESULTS AND DISCUSSION}

\section{Synthesis of title compounds (VIla-VIlh)}

Physical data of the intermediates and the title compounds are given in Table 1.

\section{Spectral analysis of intermediates (II, III, Va-Vh) and the title compounds (VIla-VIIh)}

The intermediates and the title compounds were characterised by IR $\left(\mathrm{KBr}, \mathrm{cm}^{-1}\right)$ which showed the presence of prominent peaks in all the molecules. The data is represented in Figures 1-3.

(II): 3126.74, 2938.68 (Ar C-H stretch), 1684.89 (C=O stretch), 790.85 (C-Cl stretch)

(III): 3309.99 (N-H stretch), 2946.39 (Ar C-H stretch), 1708.04 (C=O stretch), 1604.84 (N-H bend)

(Va): 3024.38 (N-H stretch), 2912.51 (Ar C-H stretch), 1645.28 (C=O stretch), 1600.92 ( N-H bend), 1548.84 ( $\mathrm{C}=\mathrm{N}$ stretch), 844.82 (Ar C-H bend)

(Vb): 3058.27 (N-H stretch), 2860.56 (Ar C-H stretch), $1682.96(\mathrm{C}=\mathrm{O}$ stretch), $1607.74(\mathrm{~N}-\mathrm{H}$ bend), 1529.62 $\left(\mathrm{C}=\mathrm{N}\right.$ stretch), $1482.36\left(\mathrm{~N}-\mathrm{CH}_{3}\right.$ stretch $), 1004.96(\mathrm{C}-\mathrm{N}$ stretch), 844.86 (Ar C-H bend)

(Vc): 3255.98 (N-H stretch), 2828.73 (Ar C-H stretch), 1682.00 (C=O stretch), 1646.32 (N-H bend), 1524.79 (C=N stretch), 844.86 (Ar C-H bend), 794.71 (C-Cl stretch)

(Vd): 3396.64 (-OH stretch), 3196.05 (N-H stretch), 2887.44 (Ar C-H stretch), 1681.93 (C=O stretch), 1600.92 ( N-H bend), 1546.91 (C=N stretch), 1263.37 (OH bend), 837.11 (Ar C-H bend)

(Ve): 3228.84 (N-H stretch), 3030.17 (Ar C-H stretch), 1647.21 (C=O stretch), 1608.63 (N-H bend), 1544.96 (C=N stretch), 850.61 (Ar C-H bend), 744.52 (C-Br stretch) 


\begin{tabular}{|c|c|c|c|c|c|c|c|}
\hline & ( & & & & IIa-VIIh) & $\begin{array}{l}\mathbf{N H} \\
\mathbf{1} \\
\mathbf{N} \\
-\mathbf{S}\end{array}$ & \\
\hline Comp. No. & $-\mathrm{R} /-\mathrm{Ar}$ & Molecular formula & $\begin{array}{c}\text { Molecular } \\
\text { weight }\end{array}$ & Yield (\%) & $\begin{array}{l}\text { Melting point } \\
\left({ }^{\circ} \mathrm{C}\right)\end{array}$ & $\operatorname{Rf}(T L C)$ & $\log P$ \\
\hline II & $-\mathrm{Cl}$ & $\mathrm{C}_{13} \mathrm{H}_{9} \mathrm{ClO}$ & 216.66 & 70.83 & $112-114$ & 0.62 & 3.45 \\
\hline III & $-\mathrm{NH}-\mathrm{NH}_{2}$ & $\mathrm{C}_{13} \mathrm{H}_{12} \mathrm{~N}_{2} \mathrm{O}$ & 212.25 & 78.83 & $180-182$ & 0.69 & 2.15 \\
\hline Va & & $\mathrm{C}_{20} \mathrm{H}_{18} \mathrm{~N}_{2} \mathrm{O}$ & 302.37 & 70.02 & $200-202$ & 0.60 & 3.83 \\
\hline Vb & & $\mathrm{C}_{22} \mathrm{H}_{23} \mathrm{~N}_{3} \mathrm{O}$ & 345.44 & 74.08 & $198-200$ & 0.62 & 3.99 \\
\hline Vc & & $\mathrm{C}_{20} \mathrm{H}_{17} \mathrm{CIN}_{2} \mathrm{O}$ & 336.81 & 64.00 & $220-222$ & 0.68 & 4.54 \\
\hline Vd & & $\mathrm{C}_{20} \mathrm{H}_{18} \mathrm{~N}_{2} \mathrm{O}_{2}$ & 318.37 & 69.02 & 210-212 & 0.57 & 3.11 \\
\hline Ve & & $\mathrm{C}_{20} \mathrm{H}_{17} \mathrm{BrN}_{2} \mathrm{O}$ & 381.27 & 62.00 & 280-282 & 0.70 & 4.69 \\
\hline Vf & & $\mathrm{C}_{19} \mathrm{H}_{17} \mathrm{~N}_{3} \mathrm{O}$ & 303.36 & 50.04 & $218-220$ & 0.56 & 2.33 \\
\hline $\mathbf{V g}$ & & $\mathrm{C}_{20} \mathrm{H}_{17} \mathrm{~N}_{3} \mathrm{O}_{3}$ & 347.37 & 72.32 & $210-212$ & 0.62 & 3.57 \\
\hline Vh & & $\mathrm{C}_{21} \mathrm{H}_{20} \mathrm{~N}_{2} \mathrm{O}_{2}$ & 332.4 & 66.06 & 216-218 & 0.65 & 3.75 \\
\hline VIla & & $\mathrm{C}_{22} \mathrm{H}_{18} \mathrm{~N}_{2} \mathrm{O}_{2} \mathrm{~S}$ & 374.46 & 65.55 & $210-212$ & 0.70 & 4.74 \\
\hline VIllb & & $\mathrm{C}_{24} \mathrm{H}_{23} \mathrm{~N}_{3} \mathrm{O}_{2} \mathrm{~S}$ & 417.52 & 52.08 & 216-218 & 0.58 & 4.90 \\
\hline
\end{tabular}




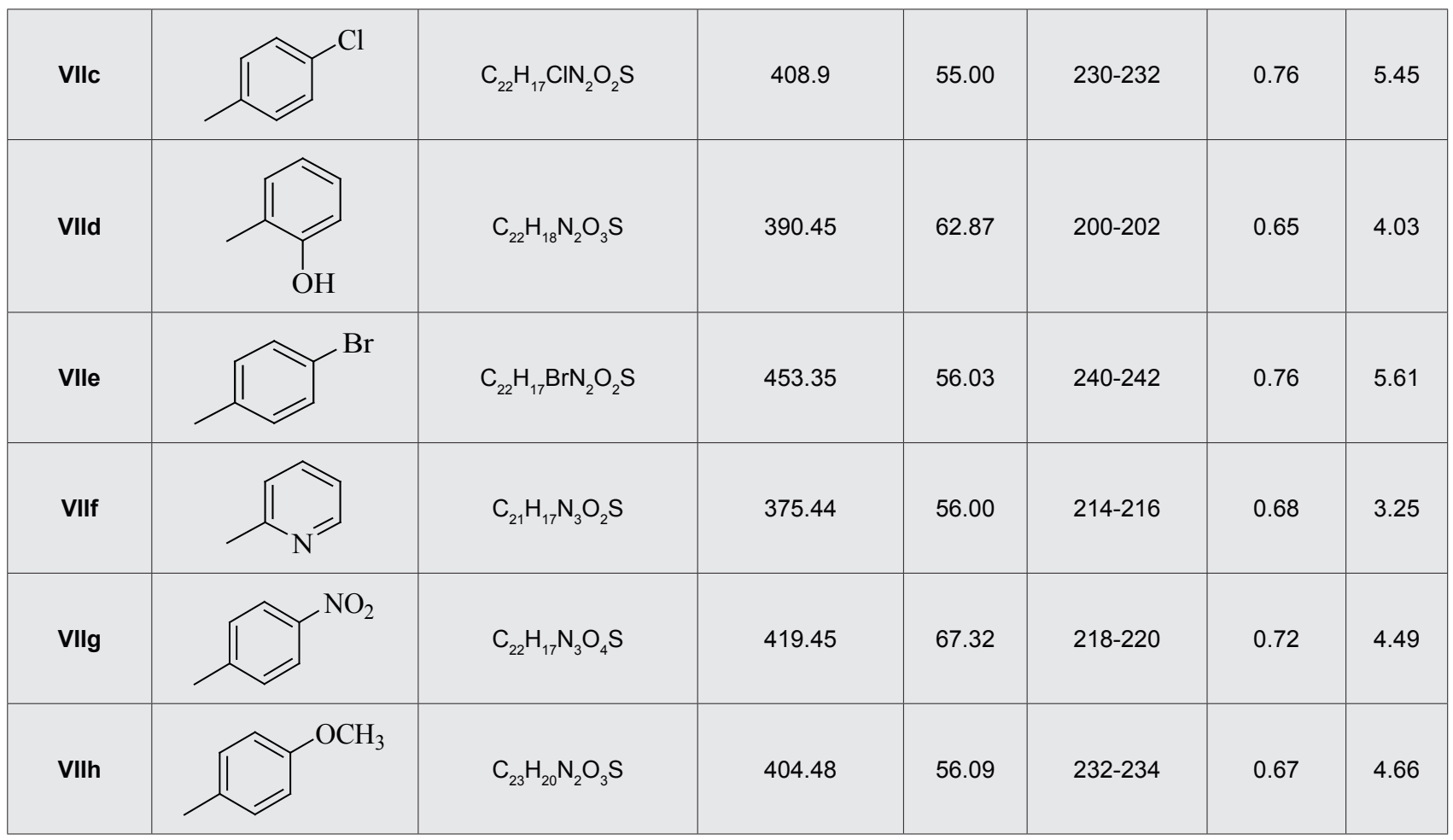
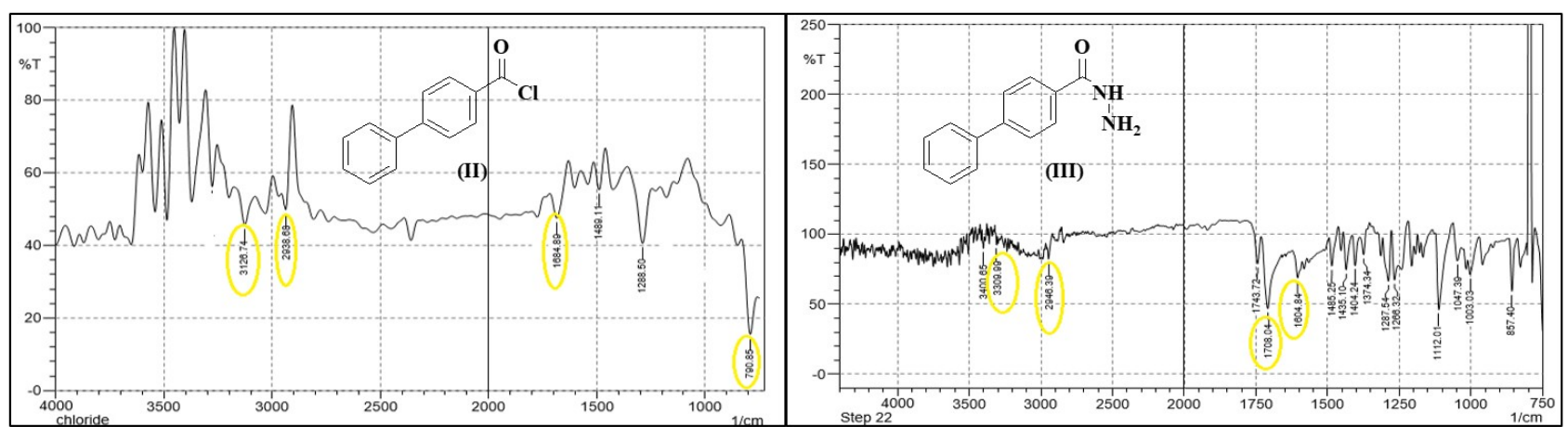

Figure 1: IR (KBr, cm-1) spectrum of 1,1-Biphenyl 4-carbonyl chloride (II) and 1,1-Biphenyl 4-carboxylic acid hydrazide (III).

(Vf): 3203.90 (N-H stretch), 2986.90 (Ar C-H stretch), 1716.72 (C=O stretch), 1631.85 (N-H bend), 1545.05 (Ar C=N stretch), 846.79 (Ar C-H bend)

(Vg): 2945.43 (N-H stretch), 2845.13 (Ar C-H stretch), 1709.00 ( $\mathrm{C}=\mathrm{O}$ stretch), 1603.88 (N-H bend), 1580.73 (Ar -NO2 stretch), 1549.87 (Ar C=N stretch), 856.43 (Ar C-H bend)

(Vh): 2946.39 (N-H stretch), 2845.13 (Ar C-H stretch), 1709.00 ( $\mathrm{C}=\mathrm{O}$ stretch), 1604.84 (N-H bend), 1485.25 (Ar C=N stretch), 1287.29 (C-H bend), 856.43 (Ar C-H bend)

(VIIa): 3233.80 (N-H stretch), 2992.69 (Ar C-H stretch), 1816.06, 1690.68 ( $\mathrm{C}=\mathrm{O}$ stretch), 1601.95 (N-H bend), 1538.30 (Ar C=C stretch), 856.43 (Ar C-H bend), 674.15 (C-S stretch)
(VIIb): 3373.64 (N-H stretch), 2902.03 (Ar C-H stretch), 1705.15, 1652.10 ( $\mathrm{C}=\mathrm{O}$ stretch), 1591.34 (N-H bend), 1422.56 (N-CH3 stretch), 1098.51 (C-N stretch), 824.60 (Ar C-H bend), 738.77 (C-S stretch)

(VIIc): 3006.19 (N-H Stretch), 2884.67 (Ar C-H stretch), 1732.15, 1669.46 ( $\mathrm{C}=\mathrm{O}$ stretch), 1614.49 (N-H bend), 1527.69 (Ar C=C stretch), 829.43 (Ar C-H bend), 758.06 (C-Cl stretch), 688.62 (C-S stretch)

(VIId): 3491.31 (OH stretch), 3298.42 (N-H stretch), 3090.10 (Ar C-H stretch), 1811.24, 1682.96 (C=O stretch), 1600.99 (N-H bend), 1445.71 ( $\mathrm{Ar} \mathrm{C}=\mathrm{C}$ stretch), 1295.28 (OH bend), 851.81 (Ar C-H, bend), 681.87 (C-S stretch)

(VIIe): 3153.75 (N-H stretch), 2886.60 (Ar C-H stretch), 1811.24, 1742.76 (C=O stretch), 1676.21 (N-H bend), 665.47 (C-S stretch), 526.59 (C-Br stretch) 


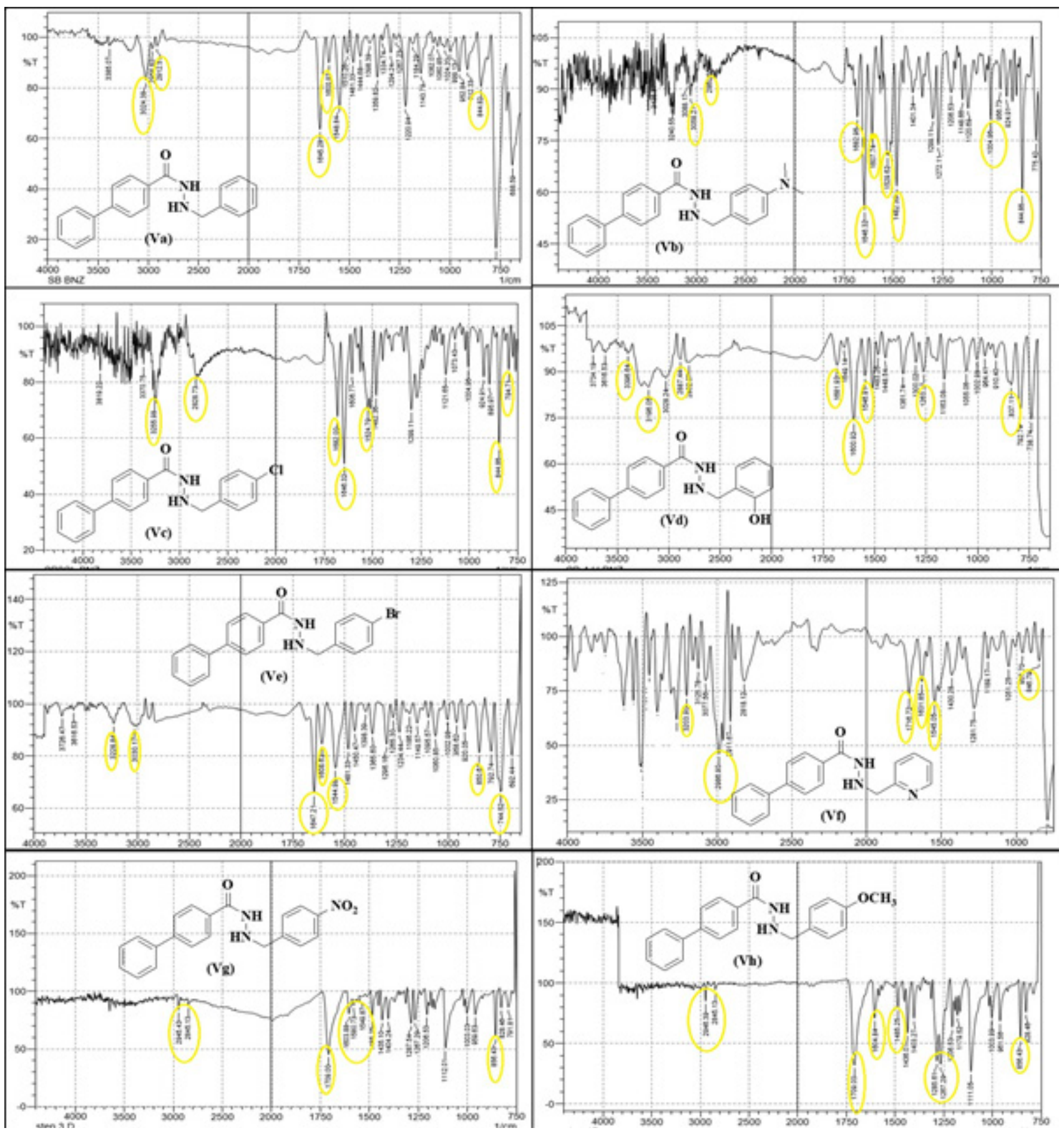

Figure 2: IR (KBr, $\left.\mathrm{cm}^{-1}\right)$ spectrum of 1,1-Biphenyl 4-carboxylic acid hydrazone (Schiff's Bases) (Va - Vh).

(VIIf): 3219.33 (N-H stretch), 2985.94 (Ar C-H stretch), 1727.33 (C=O stretch), 1623.17 (N-H bend), 1533.47 (Ar C=N stretch), 840.04 (Ar C-H bend), 666.43 (C-S stretch)

(VIIg): 3248.27 (N-H Stretch), 3002.33 (Ar C-H stretch), 1731.19, 1668.50 ( $\mathrm{C}=\mathrm{O}$ stretch), 1589.41 (N-H bend), 1521.90 (Ar -NO2 stretch), 830.39 (Ar C-H bend), 678.01 (C-S stretch)
(VIIh): 3251.16 (N-H stretch), 3086.24 (Ar C-H stretch), 1812.20, 1709.97 ( $\mathrm{C}=\mathrm{O}$ stretch), 1548.91 (N-H bend), 1229.67 (C-H bend), 837.14 (Ar C-H bend), 683.79 (C-S stretch)

The results for ${ }^{1} \mathrm{H}$ NMR (DMSO- $\mathrm{d}_{6}$ and $\mathrm{CDCl}_{3}$ as solvents and TMS was internal standard), Mass spectral analysis and elemental analysis (carbon, hydrogen, nitrogen) for representative compounds are depicted in Figures 4-13. 

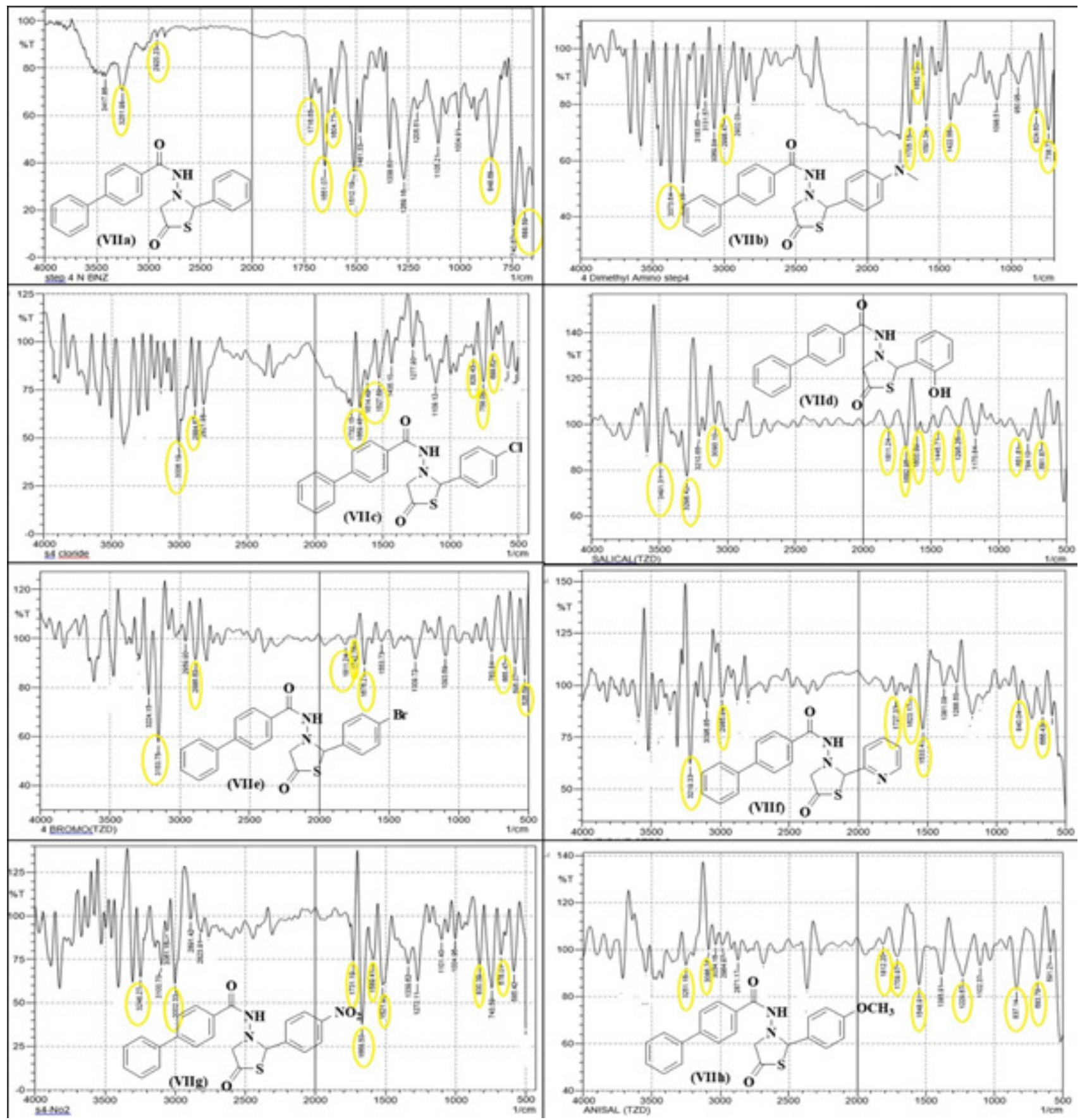

Figure 3: IR $\left(\mathrm{KBr}, \mathrm{cm}^{-1}\right)$ spectrum of 4-Thiazolidinone derivatives (VIla - VIIh).

\section{Antimicrobial evaluation of title compounds (VIla- VIIh)}

Figures 14 and 15 confirmed that all the tested compounds possess antibacterial and antifungal activity against the tested bacterial and fungal strains. However, the antimicrobial activity of the synthesized compounds against the tested organisms was found to be less than that of the standard antibacterial drug Ciprofloxacin and standard antifungal drug Fluconazole at their tested dose levels.

\section{CONCLUSION}

Novel 4-thiazolidinone derivatives were synthesized and subjected to spectroscopic analysis which confirmed the proposed structure of these compounds. IR, ${ }^{1} \mathrm{H}$ NMR, mass and elemental analysis confirmed the molecular structures of these compounds. These compounds were further evaluated for antimicrobial activities, the results of which revealed that some compounds possessed moderate antifungal activity and good antibacterial activity against fungal and bacterial strain respectively. It 


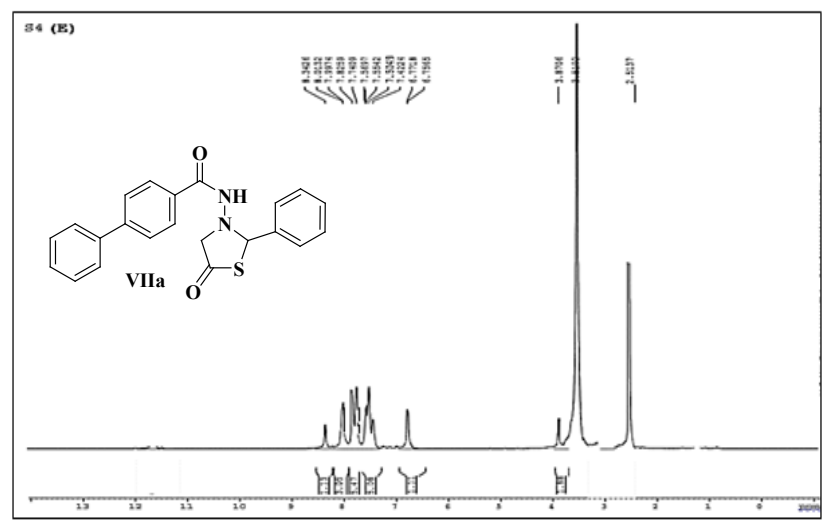

Figure 4: ${ }^{1} \mathrm{H}$ NMR (DMSO-d6, $\delta$, ppm) spectrum of 3-((1,1-Biphenyl 4-ylcarbonyl)-amino)-2-phenyl-1,3-thiazolidin4-one (Vlla); 8.3 ( $\left.{ }^{1} \mathrm{H}, \mathrm{s},-\mathrm{NH}\right), 8.01-7.4(14 \mathrm{H}, \mathrm{m}, \mathrm{Ar}-\mathrm{H}), 6.7\left({ }^{1} \mathrm{H}, \mathrm{s}\right.$, -NCH), $3.8\left({ }^{1} \mathrm{H}, \mathrm{s},-\mathrm{SCH} 2\right)$.

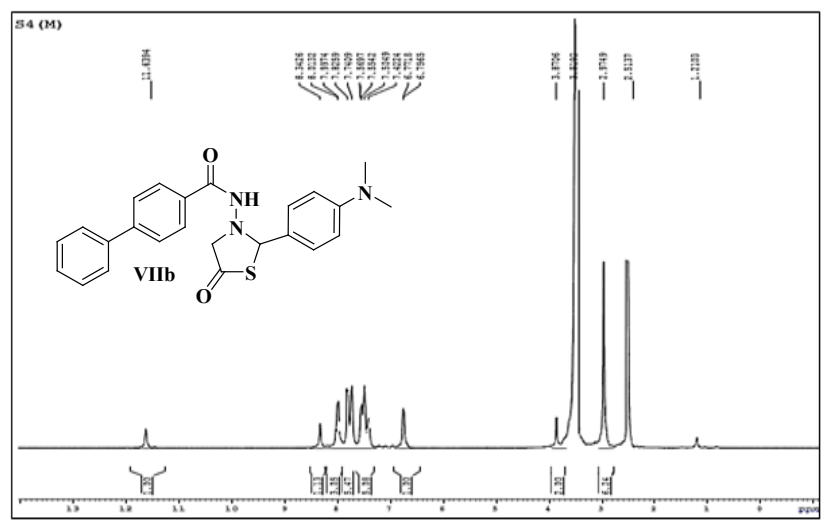

Figure 5: ' $1 \mathrm{H}$ NMR (DMSO-d6, $\delta$, ppm) spectrum of 3-((1,1-Biphenyl 4-ylcarbonyl)-amino)-2-(4-(dimethylamino) phenyl)-1,3-thiazolidin-4-one (VIIb); 11.6 (1H, s, -NH), 8.3-7.4 (14H, m, Ar-H), 6.7 (1H, s, -NCH), 3.8 (1H, s, -SCH2), 2.9 (6H, s, $(-\mathrm{CH} 3) 2)$.

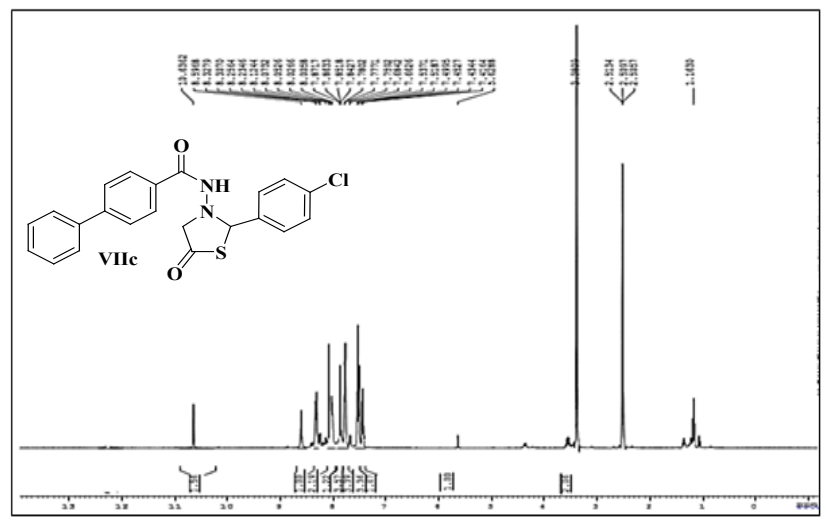

Figure 6: ${ }^{1} \mathrm{H}$ NMR (DMSO-d6, $\left.\delta, \mathrm{ppm}\right)$ spectrum of 3-((1,1-Biphenyl 4-ylcarbonyl)-amino)-2-(4-chlorophenyl)-1,3thiazolidin-4-one (VIIc); 10.6 ( $\left.{ }^{1} \mathrm{H}, \mathrm{s},-\mathrm{NH}\right), 8.5-7.4$ (14H, m, ArH), $5.6\left({ }^{1} \mathrm{H}, \mathrm{s},-\mathrm{NCH}\right), 3.3\left({ }^{1} \mathrm{H}, \mathrm{s},-\mathrm{SCH} 2\right)$.

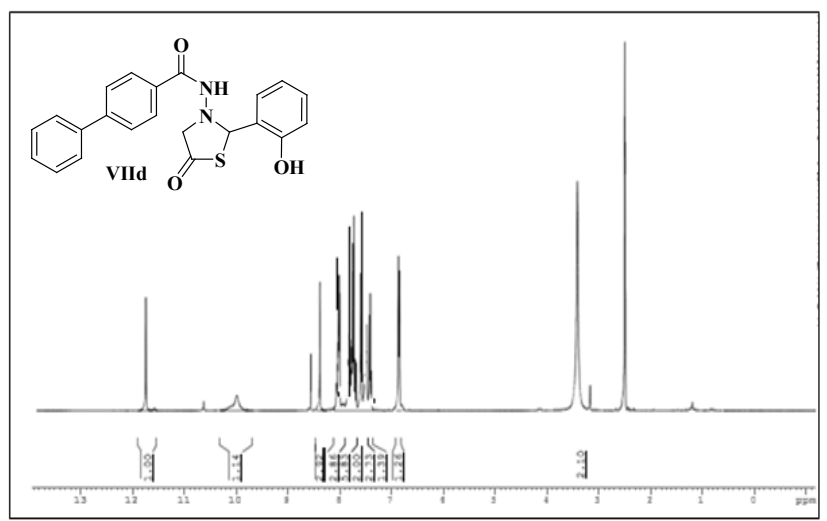

Figure 7: ${ }^{1} \mathrm{H}$ NMR (DMSO-d6, $\left.\delta, \mathrm{ppm}\right)$ spectrum of 3-((1,1-Biphenyl-4ylcarbonyl)-amino)-2-(2-hydroxyphenyl)-1,3thiazolidin-4-one (VIId); $11.7\left(\mathrm{~s},{ }^{1} \mathrm{H},-\mathrm{OH}\right), 8.5-7.4(\mathrm{~m}, 14 \mathrm{H}, \mathrm{ArH})$, 9.9 (s, $\left.{ }^{1} \mathrm{H},-\mathrm{NH}\right), 6.8\left(\mathrm{~s},{ }^{1} \mathrm{H},-\mathrm{NH}\right), 6.8\left(\mathrm{~s},{ }^{1} \mathrm{H},-\mathrm{NCH}\right), 3.4-3.1\left(\mathrm{~s},{ }^{1} \mathrm{H}\right.$, -SCH2).

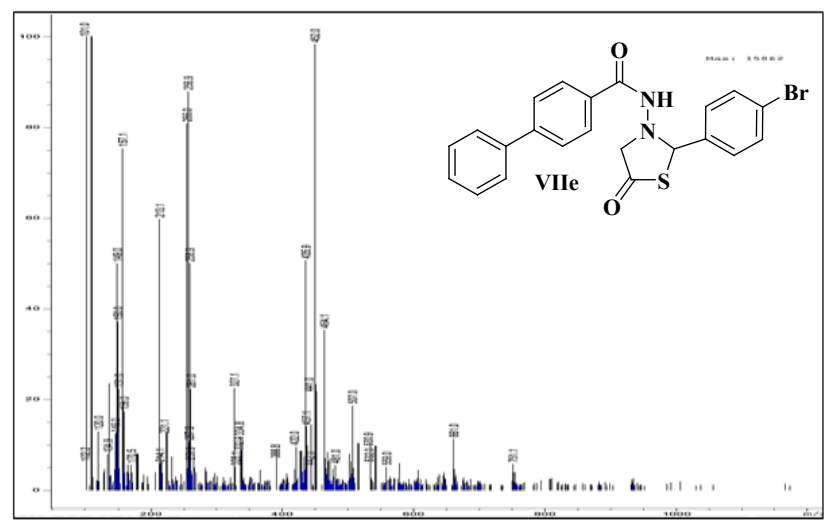

Figure 8: Mass spectrum $(\mathrm{m} / \mathrm{z})$ of 3-((1,1-Biphenyl4ylcarbonyl)amino)-2-(4-bromophenyl)-1,3-thiazolidin-4-one (VIle); 452 (100\%), 255 (56.41\%), 213 (47.12\%), 157 (34.73\%).

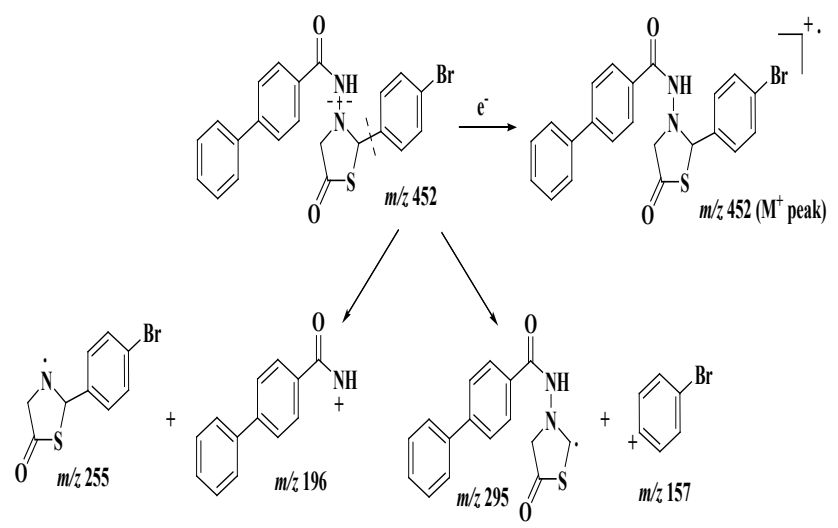

Figure 9: Fragmentation pattern for 3-((1,1-Biphenyl4ylcarbonyl)amino)-2-(4-bromophenyl)-1,3-thiazolidin-4-one (VIle). 


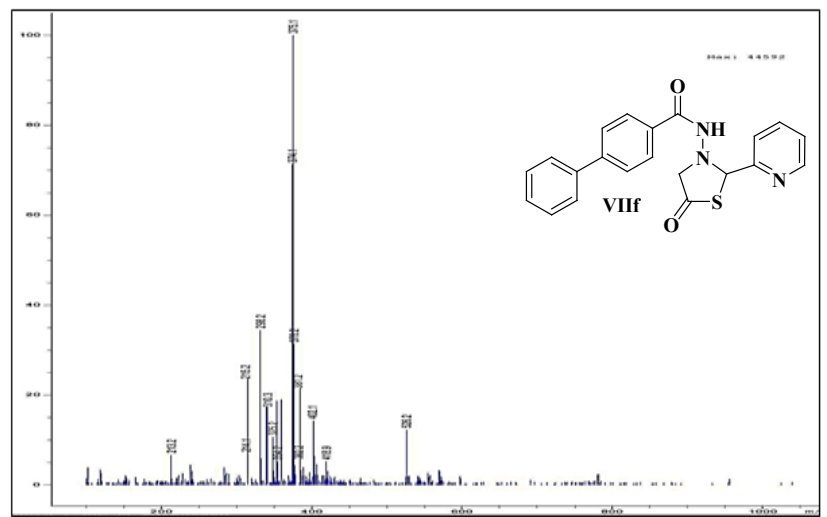

Figure 10: Mass spectrum $(\mathrm{m} / \mathrm{z})$ of 3-((1,1-Biphenyl-4 ylcarbonyl)amino)-2-(pyridin-2-yl)-1,3-thiazolidin-4-one (VIIf); 375 (100\%), 374 (99.73\%), 298 (79.46\%).

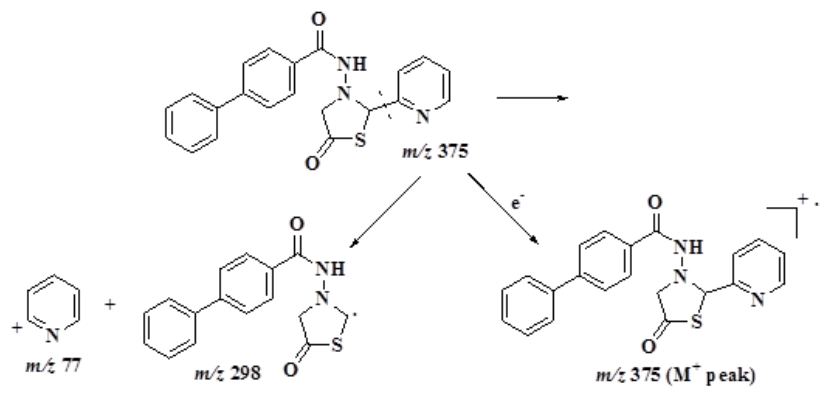

Figure 11: Fragmentation pattern for 3-((1,1-Biphenyl-4 ylcarbonyl)amino)-2-(pyridin-2-yl)-1,3-thiazolidin-4-one (VIIf).

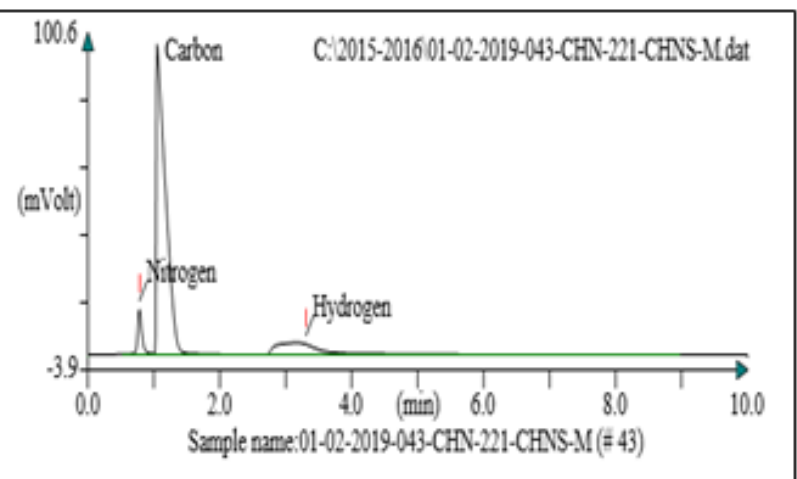

Figure 12: CHN Spectrum of 3-((1,1-Biphenyl-4-ylcarbonyl) amino)-2-(4-nitrophenyl)-1,3-thiazolidin-4-one (VIIg); Calculated Value - N (10.02\%), C (63.00\%), H (4.0\%), Obtained Value - N (10.08\%), C (62.60\%), H (4.02\%).

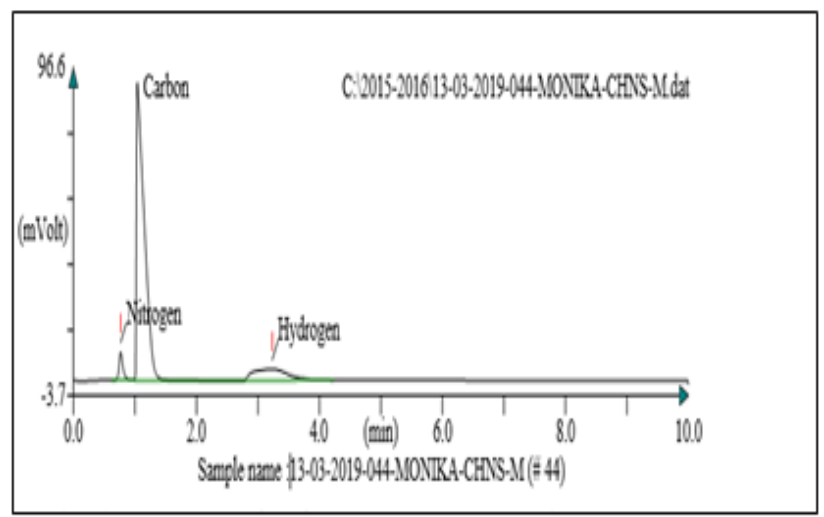

Figure 13: CHN Spectrum of 3-((1,1-Biphenyl-4-ylcarbonyl) amino)-2-(4-methoxy-phenyl)-1,3-thiazolidin-4-one (VIIh); Calculated Value - N (6.93\%), C (68.31\%), H (4.9\%), Obtained Value - N (6.10\%), C (68.00\%), H (4.06\%).

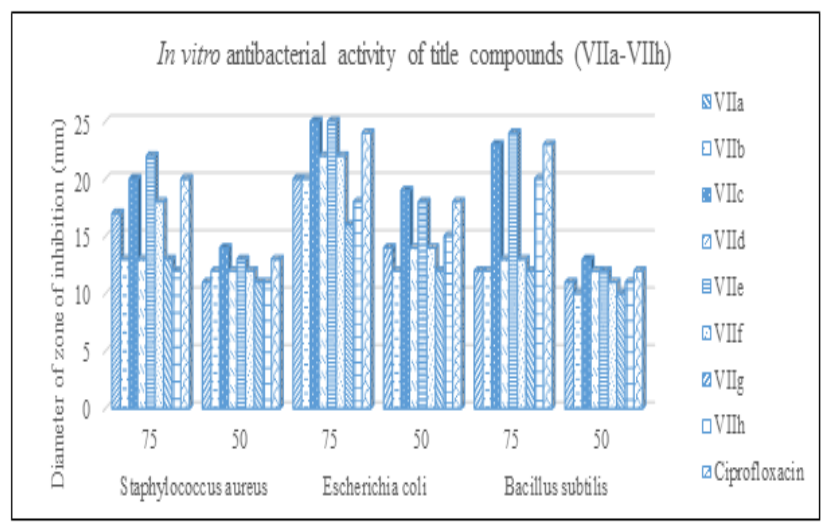

Figure 14: In vitro antibacterial activity of title compounds (VIla-VIIh).

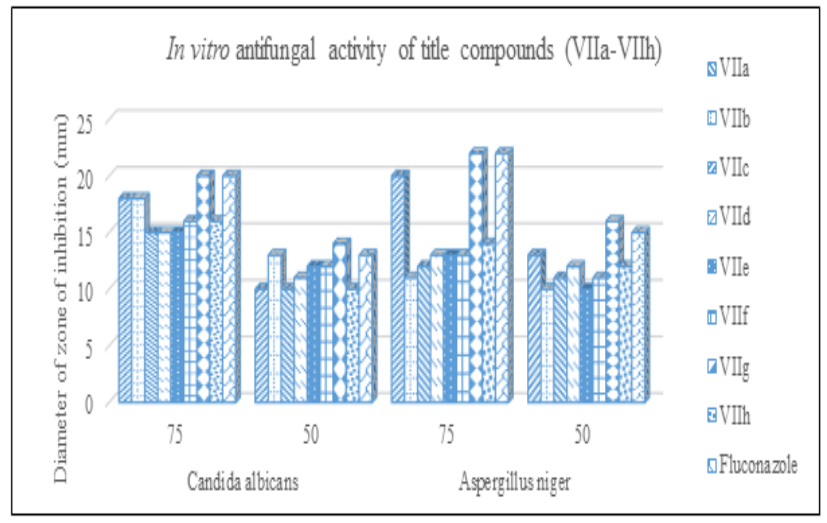

Figure 15: In vitro antifungal activity of title compounds (VIla-VIIh). 
was concluded that the compounds containing electron withdrawing groups $\left(-\mathrm{NO}_{2},-\mathrm{CI},-\mathrm{Br}\right)$ on the aromatic ring showed improved antimicrobial activity. The results of antimicrobial study indicated that the presence of halogen moiety in VIIc and VIIe on the aromatic ring showed improved antibacterial activity, whereas the presence of nitro group in VIIg on the aromatic ring showed improved antifungal activity of substituted 4-thiazolidinone.

\section{ACKNOWLEDGEMENT}

The authors thank the college management who provided all the facilities for carrying out the research work. The authors also acknowledge Sophisticated Analytical Instrument facility (SAIF), Punjab for NMR and Mass spectra studies.

\section{CONFLICT OF INTEREST}

Th authors declare no Conflict of Interest.

\section{ABBREVIATIONS}

TLC: Thin Layer Chromatography; UV: Ultraviolet; FTIR: Fourier Transform Infrared; NMR: Nuclear Magnetic Resonance; TMS: Tetramethylsilane; KBr: Potassium bromide; DMSO: Dimethyl sulfoxide; $\mathrm{CDCl}_{3}$ : Deuterated chloroform.

\section{PICTORIAL ABSTRACT}

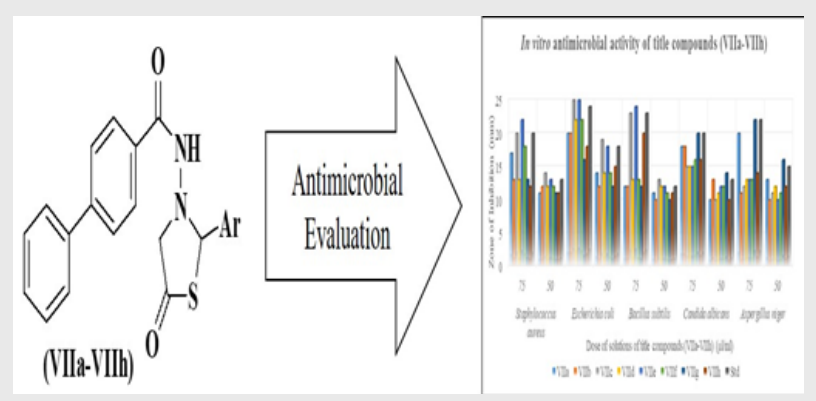

\section{About Authors}

Ms. Monika Shirke, She has been a Research Scholar, Department of Pharmaceutical Chemistry, Vivekanand Education Society College of Pharmacy, Chembur, Mumbai, Maharashtra, INDIA.

\section{REFERENCES}

1. Sharma R, Nagda DP, Talesara GL. Synthesis of various isoniazidothiazolidinones and their imidoxy derivatives of potential biological interest. Arkivoc. 2006;1(1):1-12.

2. Kilburn JP, Lau J, Jones RCF. 1,3,4-Oxadiazole formation: A novel solid support strategy. Tet Lett. 2001;42(13):2583-6.

3. Dua R, Shrivastava S, Sonwane SK, Shrivastava SK. Pharmacological Significance of Synthetic Heterocycles Scaffold: A Review. Adv Biol Res. 2011;5(3):120-44.

4. Gomtsyan A. Heterocycles in Drugs and Drug Discovery. Chem Het Comp. 2012;48(1):7-10.

5. Ravichandran S, Karthikeyan E. Microwave Synthesis: A Potential Tool for Green Chemistry. Int J ChemTech Res. 2011;3(1):466-70.

6. Kucukguzel SG, Oruc EE, Rollas S, Sahin F, Ozbek A. Synthesis, Characterisation and Biological Activity of Novel 4-thiazolidinones, 1,3,4-oxadiazoles and Some Related Compounds. Eur J Med Chem. 2002;37(3):197-206.

7. Bonde D, Gaikwad J. Synthesis and Preliminary Evaluation of Some Pyrazine Containing Thiazolines and Thiazolidinones as Antimicrobial Agents. Bioorg Med Chem. 2004;12(9):2151-61.

8. Malhotra M, Rawal RK, Malhotra D, Dhingra R, Deep A, Sharma PC. Synthesis, characterization and pharmacological evaluation of (Z)-2-(5(biphenyl-4-yl)-3-(1-(imino)ethyl)-2,3-dihydro-1,3,4-oxadiazol-2-yl)phenol derivatives as potent antimicrobial and antioxidant agents. Arabian J Chem. 2017;10(1):S1022-31.

9. Barreca ML, Chimirri A, Luca LD, Monforte AM, Monforte P, Rao A, et al. Discovery of 2,3-diaryl-1,3-thiazolidin-4-ones as potent anti-HIV-1 agents. Bioorg Med Chem Lett. 2001;11(13):1793-6.

10. Deep A, Jain S, Sharma PC, Verma P, Kumar M, Dora CP. Design and Biological Evaluation of biphenyl-4-carboxylic acid hydrazide-hydrazone for antimicrobial activity. Acta Poloniae Pharm-Drug Res. 2010;67(3):255-9.

11. Vogt PF, Miller MJ. Development and Applications of Amino Acid-Derived Chiral Acylnitroso Hetero Diels-Alder Reactions. Tetrahedron. 1998;54(8):1317.

12. Verma A, Saraf SK. 4-Thiazolidinone: A biologically active scaffold. Eur J Med Chem. 2008;43(5):897-905.

13. Andrews M, Thomas S. Determination of Minimum Inhibitory Concentration. J Antimicrob Chemother. 2001;48(Suppl 1):5-16.

14. Isenberg HD. American Society for Microbiology Washington, D.C. 1992.
Ms. Monali Gangthade, has been a Research Scholar, Department of Pharmaceutical Chemistry, Vivekanand Education Society College of Pharmacy, Chembur, Mumbai, Maharashtra, INDIA.

Mr. Pratip K. Chaskar, has been working as an Assistant Professor, Department of Pharmaceutical Chemistry, D Y Patil University School of Pharmacy, Nerul, Navi Mumbai, Maharashtra, India. He has around 10 years of professional experience including teaching and research. He has more than 30 scientific publications. He serves as a reviewer of several reputed scientific journals. He has been a key member of many of the college-related activities. He is a life member of the Indian Pharmaceutical Association. 
Dr. Rakesh R. Somani, is working as a Professor and the Principal with newly established D Y Patil University School of Pharmacy, Navi Mumbai. He has completed his Ph.D. degree in Synthetic Chemistry and has been involved in teaching and research for the past 19 years. He has more than 40 peer-reviewed research publications to his credit. His major research area includes heterocyclic chemistry, green chemistry and drug designing in Cancer and Tuberculosis treatment. He has established research collaborations with various National and International Organizations such as National Institute of Health, USA; CDRI, Lucknow, OIDD Programme, USA, Rega Institute, Belgium etc. his one of the research publications was awarded as Best Research Paper by Indian Drugs Manufacturing Association (IDMA) in 2014. He has suervised more than 41 Post Graduate and 2 Ph.D. students. Apart from academic responsibilities, he has been proactively working in accreditation, industrial collaborations, innovation-incubation and entrepreneurship development activities.

Cite this article: Shirke M, Gangthade M, Chaskar P, Somani R. Synthesis, Characterization and Pharmacological Evaluation of Biphenyl Based 4-Thiazolidinones. Indian J of Pharmaceutical Education and Research. 2021;55(2):36373. 